\title{
Kontribusi Etnomatematika dalam Pembelajaran Matematika Tingkat Sekolah Dasar
}

\author{
Gita Kencanawaty ${ }^{1}$, Chatarina Febriyanti ${ }^{2}$, Ari Irawan ${ }^{3 *}$ \\ 1,2,3 Universitas Indraprasta PGRI \\ *ari_irawan@unindra.ac.id
}

Diterima: Maret 2020. Disetujui: Mei 2020. Dipublikasikan: Juli 2020.

\begin{abstract}
ABSTRAK
Etnomatematika merupakan budaya yang memiliki unsur matematika. Tujuan dari penelitian ini adalah untuk mengungkap bagaimana kontribusi penerapan etnomatematika pada proses pembelajaran matematika, khususnya untuk siswa sekolah dasar. Bagaimana hasil pembelajaran yang menerapkan etnomatematika dalam proses pembelajaran matematika dikelas. Metode penelitian yang digunakan adalah kualitatif deskriptif, peneliti melakukan kegiatan observasi atau pengamatan secara langsung serta wawancara kepada pihak terkait atau narasumber tentang pembelajaran menggunakan etnomatematika. Hasil dari penelitian ini adalah (1) penerapan pembelajaran matematika yang diterapkan dengan konsep etnomatematika mempunyai kontribusi yang besar dalam membantu pemahaman siswa terhadap materi pembelajaran khususnya materi bangun datar dan bangun ruang, kontribusinya jelas terlihat dalam peningkatan hasil belajar matematika siswa, dan (2) terjadi peningkatan hasil belajar siswa karena adanya penerapan pembelajaran dengan konsep etnomatematika hal ini terlihat dari nilai hasil ulangan harian siswa dan juga terlihat dari antusiasme siswa ketika guru sedang mengajar menggunakan etnomatematika sebagai sumber dan bahan ajar pembelajaran matematika.
\end{abstract}

Kata kunci:etnomatematika sunda, sekolah dasar, pembelajaran matematika.

\begin{abstract}
Ethnomathematics is a culture that have an element of mathematics.Objectives of the study are to uncover the contribution of the application of etnomatematika to the process to learning mathematics, especially for primary school student andthe learning outcomes that apply ethnomatematics in the learning process of mathematics in the classroom.The research method used was descriptive qualitative, researchers conducted direct observationsand interview to the teachers and students about learning using ethnomathematics. The result of this research are (1) the application of learning mathematics that is applied by the concept of etnomatematika have a significant contribution in helping students understanding of learning especially two dimensional three dimensional subject matter and (2) students' learning outcomes has increased because the presence of the application of learning with the concept of the etnomatematika this can be seen from the results of daily remedial students and can also be seen from enthusiasm students as the teacher was teaching use etnomatematika as a source of and teaching materials learning mathematics.
\end{abstract}

Keywords: ethnomathematics, elementary school, mathematics learning.

How to Cite: Kencanawaty, G., Irawan, A., \&Febriyanti, C.(2020). Kontribusi Etnomatematika dalam Pembelajaran Matematika Tingkat Sekolah Dasar. Journal of Medives: Journal of Mathematics Education IKIP Veteran Semarang, 4(2), 255-262. 


\section{PENDAHULUAN}

Keterkaitan budaya dan pendidikan merupakan hal yang tidak dapat dipisahkan. Budaya mengajarkan nilainilai luhur dari nenek moyang tentang bagaimana tatacara bersikap dan berinteraksi dengan baik kepada sesama. Pendidikan menjadi tolak ukur kebudayaan suatu daerah apakah berkembang atau tidak. Dengan demikian pendidikan dan budaya saling melengkapi satu dengan lainya seperti pemerintah menjadikan satu kementrian pendidikan dan kebudayaan yang latar belakangi filosofi bahwa budaya dan pendidikan saling berkaitan.

Pendidikan merupakan sarana dalam upaya pengembangan diri seseorang untuk menjadi labih baik. Budaya adalah suatu adat kebiasaan yang masyarakat lakukan secara ulang dan turun temurun. Matematika adalah abstraksi dalam bilangan, melakukan operasi penjumlahan, pengurangan, perkalian dan pembagian. Proses penggabuangan antara pendidikan, budaya dan matematika inilah yang melahirkan suatu konsep etnomatematika yang berarti unsur matematika yang terdapat dalam budaya masyarakat. Etnomatematika adalah berbagai hasil aktivitas matematika yang dimiliki atau berkembang di masyarakat Lampung, meliputi konsepkonsep matematika pada peninggalan budaya berupa peralatan tradisional, satuan lokal, motif kain tapis, serta permainan tradisional(M. Rakhmawati, 2016). Dimana bumi berpijak disitu langit dijunjung. Peribahasa demikian menjadi lekat dengan budaya masyarakat dimana kita bertempat tinggal maka kita harus dapat menyesuaikan dengan adat istiadat dan kebudayaan yang berlaku pada masyarakat tersebut. Etnomatematika adalah bentuk matematika yang dipengaruhi atau didasarkan budaya(Supriyani et al., 2015; Susilo \& Widodo, 2018).

Indonesia dengan keragaman budayanya sudah seharusnya memasukkan nilai-nilai budaya setempat ke dalam pembelajaran matematika, agar matema-tika tidak dianggap sebagai ilmu penge-tahuan yang jauh dari realitas kehidupan(Irfan \& Widodo, 2017; Susilo \& Widodo, 2018). Hal ini dikarenakan dalam aktivitas budaya terdapat ide-ide matematis yang dianggap sebagai hal yang penting dalam pembelajaran matematika (Prabawati, 2016). Salah satu penyebab rendahnyanilai siswa-siswi Indonesia terhadap matematika adalah karena dalam proses pembelajar-an matematika, guru umumnya masih menyajikan materi pembelajaran matematika berkonsentrasi pada latihan penyelesaian soal yang lebih bersifat prosedural(Fitri et al., 2018).Pembelajaranbermuatanetnomatematika akan sangat memungkinkan suatu materi yang dipelajari dari budaya mereka dapat membangkitkan motivasi belajar serta pemahaman suatu materi oleh peserta didik menjadi lebih mudah karena materi tersebut terkait langsung dengan budaya mereka yang merupakan aktivitas mereka sehari-hari dalam bermasyarakat(Mahendra, 2017). Proses kegiatan pembelajaran matematika untuk siswa sekolah dasar saat ini belum banyak menggunakan budaya sebagai sarana pembelajaran. 
Perkembangan pendidikan saat ini lebih kearah digital namun harus tetap diimbangi dengan pengetahuan dan pelesatrian budaya dalam pendidikan. Atas dasar demikian peneliti merasa perlu mengetahui bagaimana implementasi pendidikan matematika dengan berbasis etnomatematika sebagai pembe-lajaran dikelas untuk sekolah dasar dapat berkontribusi untuk meningkatkan kemampuan pemahaman siswa terhadap materi ajar matematika dan sebagai sarana pelesatarian budaya.

\section{METODEPENELITIAN}

Metode yang digunakan dalam penelitian ini adalah penelitian analisis deskriptif kualitatif. Proses penelitian dilakukan dengan melakukan pengamatan atau observasi kegiatan pembelajaran yang dilakukan oleh guru dan siswa di sekolah berbasis budaya. Penelitian ini menggunakan jenis penelitian kualitatifetnomatematika yaitu suatu metode penelitian berbasis budaya untuk mengkaji keterkaitannya dengan konsep matematika(Aini et al., 2019). Teknik analisis data yang digunakan adalah triangulasi artinya tim peneliti melakukan analisis setelah mendapatkan data melalui observasi, wawancara dan dokumentasi lalu dianalis oleh peneliti dan konsultasi dengan pakar pendidikan matematika dan pakar etnomatematika.

Peneliti juga melakukan wawanca-ra secara langsung kepada beberpa pihak terkiat yaitu kepala sekolah, guru, dan siswa. Penelitian ini dilakukan di SDNegeri 8 Ciseureuh Kahuripan Pajajaran Purwakarta yang merupakan sekolah berbasis budaya yang ada di Kabupaten Purwakarta.
Sekolah ini merupakan pilot project dari sekolah berbasis budaya khas Sunda.

\section{HASIL DAN PEMBAHASAN}

Kegiatan pembelajaran yang dilakukan di kelas pada sekolah yang memang menerapkan budaya dalam kegiatan pembelajaran kesehariannya ada beberapa istilah dalam bahasa Sunda yang menjadi ciri khas sekolah tersebut dalam menerapkan pendidikannya. Terdapat lima karakter pinunjul murid Kahuripan Pajajaran adalah (1) Pinunjul Kéwes-Gandes dengan indikator: Berséka, Rapih dina raksukan, Luyu kana dinten nganggo raksukan; (2) Pinunjul Tatakrama Basa dengan indikator: Tara sasauran kasar, Lentong nyarita merenah, Mahér Basa Sunda; (3) Pinunjul Réngkak Paripolah dengan indikator: Sopan dina sikep sareng paripolah, Hampang birit, Tumut kana kasauran guru; (4) Pinunjul Motékar Rancagé dengan indikator: Motékar dina diajar, Rancagé dina gawé, Calakan dina pangajaran; dan (5) Rajin bebere-sih, Tulatén ngarawat pepelakan, Singer kana padamelan. Berdasarkan lima karakter tersebut diharapkan siswa menjadi mandiri dan disiplin. Kegiatan pembiasaan ini tidak semata ini dilakukan di sekolah akan tetapi juga bersinergi dengan orang tua siswa dalam menerapkan disiplin dan rapih dalam melaksanakan kegiatan yang teratur.

Terdapat tema dalam kegiatan keseharian yang tiap hari memiliki tema yang berbeda dengan tujuh poe atikanantara lain Senin sebagai Ajeg Nusanta-ra, Selasa Mapag Buana, Rabu Maneuh di Sunda, Kamis Nyanding 
Wawangi, Jumat Nyucikeun Diri, dan hari Sabtu-Minggu Betah di Imah.

Dalam Ajeg Nusantara, guru mengajar di kelas menjelaskan tentang aneka ragam Nusantara. Baik keadaan alamnya maupun kebudayaannya. Kemudian Mapag Buana berarti menjemput dunia. Guru menjelaskan peradaban dunia yang luas, bagaimana pemikiran dan ideologi yang berkembang, termasuk industri di dalamnya. Selanjutnya Maneuh di Sunda mempela-jari berbagai hal yang berhubungan dengan kasundaan, karena Sunda memiliki kekayaan budaya yang luar biasa, yang bukan hanya untuk disanjung atau sekadar dibanggakan, akan tetapi harus maneuh dalam perilaku sehari-hari. Kamis Nyanding Wawangi siswa diajarkan oleh guru tentang nilai-nilai estetika, nilai kesemestaan, nilai alam dengan pendekatan sastra dan seni. Pada hari Nyanding Wawangi siswadan guru boleh mengenakan pakaian bebas tetapi rapi. Kemudian Jumat nyucikeun diri, hari untuk menyucikan diri yang selaras dengan akidah keislaman. Contohnya siswa mengaji di sekolah, kontemplatif ke dalam hati dan kepribadian, bersih diri dan bersih lingkungan sekolah yang berdampak kepada kenyamanan suasana pembelajaran. Sedangkan pada hari Sabtu dan Minggu Betah di imah, guru diharapkan tidak memberikan tugas apapun kepada siswa, dengan tujuan siswa diberikan waktu lebih dekat dengan orang tuanya, bercengkrama dengan keluarga sehingga tercipta nuansa keakraban dan keluarga yang harmonis.
Masyarakat Suku Sunda di Provinsi Jawa Barat mempunyai tradisi-

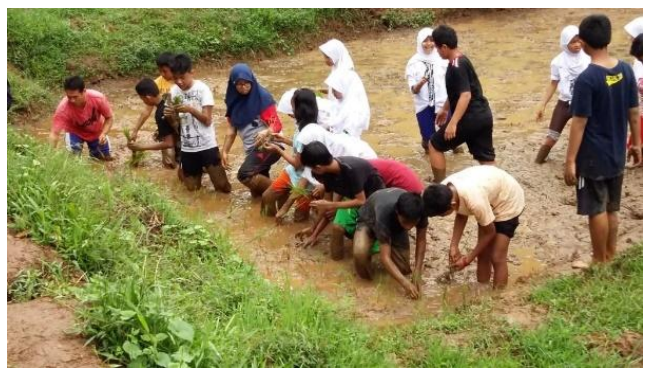

Gambar 1. Proses Menanam Padi di Sawah

tradisi hidup masyarakat yang turunmenurun dari nenek moyangnya seperti aktivitas budaya dan permainan tradisio-nal. Aktivitas budaya di pedusunan sangat kental dengan kegiatan berenang dan memancing di sungai, bersiul, membuat kerajinan bambu, mengembala ternak, membajak sawah, dan lain-lain.Sedangkan permainan tradisional adalah main rebutan,layang-layang, loncat tali,gasing,dan lain-lain. Karena aktivitas budaya dan permainan tradisional sering dilakukan oleh masyarakat, maka kegiat-an tersebut sudah mendarah daging dalam diri anak-anak(Muzdalipah \& Yulianto, 2015).Kaitannya dengan pembelajaran matematika dengan konsep dan pendekatan etnomatematika contohnya adalah dengan melakukan kegiatan menanam sawah yang memiliki arti dan makna. Kegiatan menanam sawah memiliki konsep matematika diantaranya adalah jarak antar tanaman harus sama dan jangan terlalu dekat ini dimaksudkan agar tanaman mendapatkan nurtisi makanan dan mineral yang cukup. Menanam sawah juga tidak maju ke depan akan tetapi kegiatan menanam sawah mundur kebelakang, kegiatan ini 
dimaksudkan agar ketika tanaman yang sudah ditanam tidak terinjak maka dengan demikian cara menanam padi di sawah dengan cara mundur. Kegiatan ini selain mengasah kemampuan afektif dan psikomotorik siswa. Proses pembelajar-an dilakukan dialam terbuka maka siswa juga mendapatkan suasana baru, kegiat-an ini bertujuan untuk siswa dapat lebih menghargai beras dan nasi yang dimakan harus secukupnya, karena siswa dapat merasakan dan terjun langsung dalam proses produksi dari pada sampai menjadi beras.

Pembelajaran

berbasis budayamerupakan suatu model pendekatan pembelajaran yang lebih mengutamakan aktivitas siswa dengan berbagai ragam latar belakang budaya yang dimiliki, diintegrasikan dalam proses pembelajar-an bidang studi tertentu, dan dalam penilaian hasil belajar dapat mengguna-kan beragam perwujudan penilaian(Ekowati et al., 2017). Proses kegiatan pembelajaran dengan konsep etnomate-matika harus dapat guru terapkan, guru dituntut untuk kreatif dalam menyajikan pembelajaran yang menarik dan bermak- na dengan alat peraga sederhana yang ada di lingkungan sekitar baik dirumah ataupun yang ada disekitar sekolah. pembelajaran ini dimaksudkan untuk dapat memberikan kesempatan kepada siswa berimajinasi dan berpraktek dengan segala keterbatasan sehingga hal ini dapat mengasah kreativitas siswa dalam memanfaatkan barang-barang dirumah maupun barang yang sudah tidak terpakai sebagai sarana pembelajaran bagi siswa.

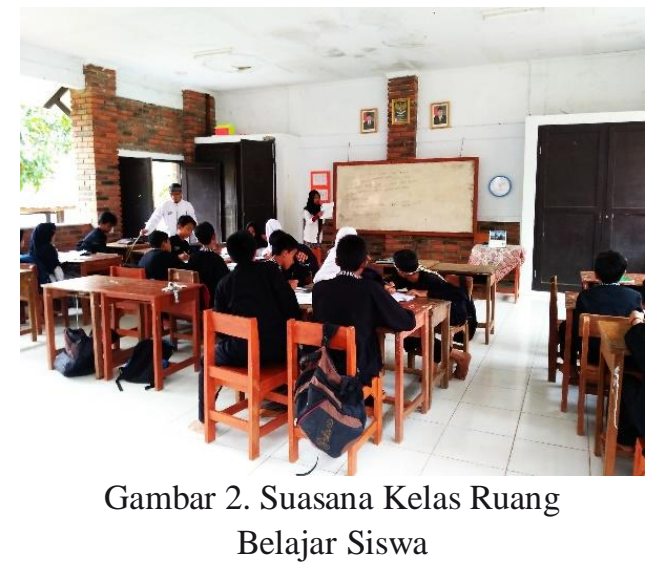

Kegiatan pembelajaran yang dilakukan oleh siswa kombinasi antara di kelas dan diluar kelas. Khusus desain kelas semi terbuka, artinya kegiatan yang dilakukan dikelas juga dapat dilihat dan disaksikan dari luar tanpa adanya jendela. Hal ini dimaksudkan agar siswa dapat merasakan sejuknya udara dan lebih menyatu kepada alam sehingga pembelajaran menjadi lebih nyaman dan lebih efektif dan efisien.

Etnomatematika adalah suatu pendekatan pengembangan pendidikan yang digunakan untuk mengkonstruksi bagaimana matematika diadaptasi dari sebuah budaya dan selanjutnya digunakan dalam kegiatan pembelajaran matematika(Marsigit, 2016).Tidak hanya konsep-konsep barang akan tetapi kegiatan sehari-hari siswa dalam permainan tradisional juga dapat diterapkan sebagai pembelajaran. Permainan tradi-sional tidak hanya mengandung unsur kesenangan tetapi juga mengandung nilai-nilai budaya dan dapat melatih kecakapan dalam berpikir dan berhitung(Risdiyanti \& Prahmana, 2018). Penerapan pembelajaran dengan konsep etnomatematika ini yang menjadi bagian kurikulum pendidikan sehinga siswa tidak hanya sekedar 
cerdas atau pandai dalam pelajaran, akan tetapi lebih mendalam dan lebih dari itu bagaimana etnomatematika dapan mencakup kese-luruhan aspek pendidikan baik ranah kognitif, afektif dan psiomotorik serta penanaman karakter dan budi pekerti yang luhur berasakan budaya lokal yang menjadi jati diri bangsa Indonesia.

Kontribusi yang diberikan etnomatematika membentuk karakter bangsa khususnya siswa yang menjadi subjek pendidikan. Proses pembelajaran bukan hanya bagaimana penguasaan teknologi akan tetapi bagaimana siswa dapat menjadi pribadi yang berkarakter dan berdaya saing sebagai bangsa yang cinta kepada tanah airnya dengan mengenal dan melesatarikan budaya sebagai dasar landasan penguasan ilmu pengetahuan dan teknologi. Sekolah-sekolah berstandar internasional dengan segala keunggulannya, yang bahkan menggunakan bahasa Inggris sebagai pengantar seharihari dalam mendidik anak bangsa, bukan tidak mungkin menyebabkan kecintaan pada nilai budaya bangsa mulai pudar(Wuryandani, 2015). Etnomatematika memberikan kontribusi yang besar terhadap pelesatrian budaya bangsa dalam pendidikan, dengan etnomatema-tika siswa menjadi lebih memahami dan menghargai perjuangan para pahlawan. Etnomatematika bagian dari filter diri siswa dalam memilih bagaimana menggunakan ilmu pengetahuan yang sesuai dengan budaya bangsa sehingga tidak menjadi ancaman dari luar, sebagai penangkal budaya yang tidak sesuai dengan jati diri bangsa Indonesia.
Pembelajaran matematika yang diterapkan dalam kegiatan dikelas yaitu pada saat menerapkan materi bangun datar dan bagun ruang. Siswa mengguna-kan alat peraga yaitu hidid, kukusan, tampah, dan lain sebagainya hal ini dimaksudkan oleh guru agar siswa dapat mengetahui bahwa bangun datar dan bagun ruang dalam kehidupan sehari-hari melekat pada kegiatan siswa untuk lebih mendalami bagaimana keguanaan alat tersebut untuk dapat menghitung luas, keliling, volume, dan luas per-mukaan sehingga siswa tidak hanya memahami rumus matematika dan menghitung akan tetapi lebih dari itu. Pemahaman siswa menjadi lebih kepada pengalaman pembelajaran matematika yang realistik sehingga mudah dipahami dan dimengerti serta mengakui keberadaan dan manfaat matematika dalam kehidupan seharihari.

Pembelajaran matematika yang diterapkan dengan penggunaan etnomatematika sebagai bagian dari kegiatan yang dilakukan disekolah menjadikan siswa lebih memahami manfaat dan kegunaan matematika dalam kehidupan sehari-hari karena siswa merasakan adanya manfaat dalam mempelajari matematika sehingga berimbas pada peningkatan motivasi belajar siswa, keaktifan siswa dikelas ketika kegiatan pembelajaran matematika, serta dampaknya pada peningkatan nilai hasil belajar siswa khusunya pada mata pelajaran matematika.

\section{PENUTUP}

Berdasarkan pemaparan hasil dan pembahasan tersebut maka dapat 
disimpulkan peranan etnomatematika dalam pembelajaran matematika tingkat sekolah dasar sangat besar sebagai landasan dan pondasi siswa untuk melakukan pembelajaran. Etnomatematika menjadi bagian yang tidak dapat terpisahkan dalam kehidupan masyarakat sehingga ini menjadi bagian yang penting untuk diterapkan dalam pembelajaran khususnya pembelajaran matematika pada tingkat sekolah dasar. Diharapkan etnomatematika menjadi tumbuh dan berkembang seiring dengan perkembangan inovasi dan teknologi menjadi bagian yang saling beriringan dan saling melengkapi satu sama lain.

\section{DAFTAR PUSTAKA}

Aini, Z., Afifah, N., Muslim, I., \& Hasanah, S. I. (2019). Eskplorasi Etnomatematika Budaya Kerabhen Sape Madura. Journal of Medives: Journal of Mathematics Education IKIP Veteran Semarang, 3(2), 177183.

Ekowati, D. W., Kusumaningtyas, D. I., \& Sulistyani, N. (2017). Ethnomathematica dalam Pembelajaran Matematika (Pembelajaran Bilangan dengan Media Batik Madura, Tari Khas Trenggal dan Tari Khas Madura). Jurnal Pemikiran dan Pengembangan SD, 5(2), 716721.

Fitri, E., Sari, P., \& Hartono, Y. (2018). Etnomatematika pada Kebudayaan Rumah Adat Ogan Komering Ulu Sumatera Selatan. Journal of Medives, 2(1), 137144.

Irfan, M., \& Widodo, S. A. (2017). Integrasi Agama dan Patrap
Triloka Pada Pembelajaran Matematika Untuk Membina Karakter Siswa. Sosiohumaniora: Jurnal Ilmu Sosial Dan Humaniora, 3(2), 145-152.

M. Rakhmawati, R. (2016). Aktivitas Matematika Berbasis Budaya pada Masyarakat Lampung. AlJabar: Jurnal Pendidikan Matematika, 7(2), 221-230.

Mahendra, I. W. E. (2017). Project Based Learning Bermuatan Etnomatematika dalam Pembelajar Matematika. JPI (Jurnal Pendidikan Indonesia), 6(1), 106-114. https://doi.org/10.23887/jpiundiksha.v6i1.9257

Marsigit. (2016). Pembelajaran Matematika dalam Perspektif Kekinian. Math Didactic: Jurnal Pendidikan Matematika, 2(3), 132-141.

Muzdalipah, I., \& Yulianto, E. (2015). Pengembangan Desain Pembelajaran Matematika untuk Siswa SD Berbasis Aktivitas Budaya dan Permaianan Tradisional Masyarakat Kampung Naga. Jurnal Siliwangi, 1(1), 6374.

Prabawati, M. N. (2016). Etnomatematika Masyarakat Pengrajin Anyaman Rajapolah Kabupaten Tasikmalaya. Jurnal Infinity, 5(1), 25-31.

Risdiyanti, I., \& Prahmana, R. C. I. (2018). Etnomatematika: Eksplorasi dalam Permaian Tradisonal Jawa. Journal of Medives, 2(1), 1-11.

Supriyani, Mastur, Z., \& Sugiman. (2015). Keefektifan Model Pembelajaran Berbasis Etnomatematika terhadap 
262 | Gita Kencanawaty, Ari Irawan, Chatarina Febriyanti - Kontribusi Etnomatematika dalam Pembelajaran Matematika ....

Kemampuan Pemecahan Masalah Siswa Kelas VII. Unnes Journal of Mathematics Education, 4(2), 135-141.

Susilo, B. E., \& Widodo, S. A. (2018). Kajian Etnomatematika dan Jati Diri Bangsa. Indomath: Indonesia Mathematics Edcuation, 1(2), 121-128.

Wuryandani, W. (2015). Integrasi Nilai-Nilai Kearifan Lokal dalam Pembelajaran untuk Menanamkan Nasionalisme Di Sekolah Dasar (Vol. 1, pp. 1-10). https://doi.org/10.1017/CBO9781 107415324.004 